PREPARED FOR THE U.S. DEPARTMENT OF ENERGY, UNDER CONTRACT DE-AC02-76CH03073

PPPL-3666

PPPL-3666

UC-70

Systems Analysis of a Compact Next Step

Burning Plasma Experiment

by

S.C. Jardin, C.E. Kessel, D. Meade, and C. Neumeyer

February 2002

NM|

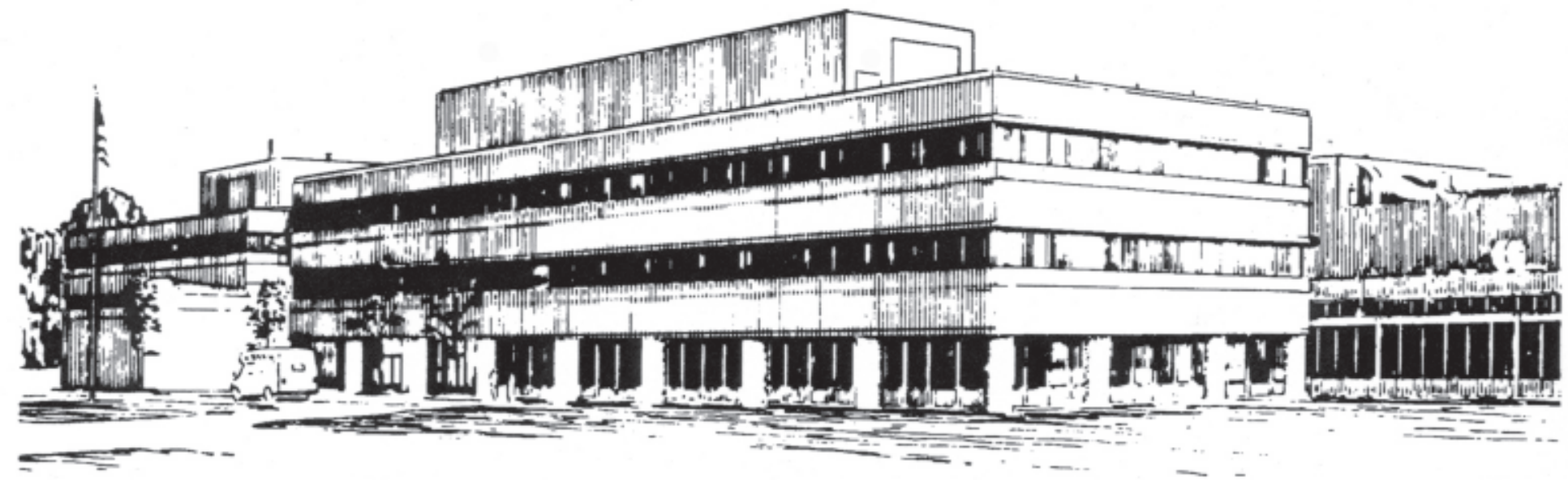

PRINCETON PLASMA PHYSICS LABORATORY PRINCETON UNIVERSITY, PRINCETON, NEW JERSEY 


\section{PPPL Reports Disclaimer}

This report was prepared as an account of work sponsored by an agency of the United States Government. Neither the United States Government nor any agency thereof, nor any of their employees, makes any warranty, express or implied, or assumes any legal liability or responsibility for the accuracy, completeness, or usefulness of any information, apparatus, product, or process disclosed, or represents that its use would not infringe privately owned rights. Reference herein to any specific commercial product, process, or service by trade name, trademark, manufacturer, or otherwise, does not necessarily constitute or imply its endorsement, recommendation, or favoring by the United States Government or any agency thereof. The views and opinions of authors expressed herein do not necessarily state or reflect those of the United States Government or any agency thereof.

\section{Availability}

This report is posted on the U.S. Department of Energy's Princeton Plasma Physics Laboratory Publications and Reports web site in Fiscal Year 2002. The home page for PPPL Reports and Publications is: http://www.pppl.gov/pub_report/

DOE and DOE Contractors can obtain copies of this report from:

U.S. Department of Energy

Office of Scientific and Technical Information

DOE Technical Information Services (DTIS)

P.O. Box 62

Oak Ridge, TN 37831

Telephone: (865) 576-8401

Fax: (865) 576-5728

Email: reports@adonis.osti.gov

This report is available to the general public from:

National Technical Information Service

U.S. Department of Commerce

5285 Port Royal Road

Springfield, VA 22161

Telephone: 1-800-553-6847 or

(703) 605-6000

Fax: (703) 321-8547

Internet: http://www.ntis.gov/ordering.htm 


\title{
Systems Analysis of a Compact Next Step Burning Plasma Experiment
}

\author{
S. C. Jardin, C. E. Kessel, D. Meade, C. Neumeyer \\ Princeton Plasma Physics Laboratory \\ P.O. Box 450 \\ Princeton, NJ 08543
}

\begin{abstract}
A new burning plasma systems code (BPSC) has been developed for analysis of a next step compact burning plasma experiment with copper-alloy magnet technology. We consider two classes of configurations: Type A, with the toroidal field (TF) coils and ohmic heating $(\mathrm{OH})$ coils unlinked, and Type $\mathrm{B}$, with the $\mathrm{TF}$ and $\mathrm{OH}$ coils linked. We obtain curves of the minimizing major radius as a function of aspect ratio, $R(A)$ for each configuration type for typical parameters. These curves represent, to first order, cost minimizing curves, assuming that device cost is a function of major radius. The Type $\mathrm{B}$ curves always lie below the Type A curves for the same physics parameters, indicating that they lead to a more compact design. This follows from that fact that a high fraction of the inner region, $\mathrm{r}<\mathrm{R}-\mathrm{a}$, contains electrical conductor material. However, the fact that the Type $\mathrm{A} \mathrm{OH}$ and $\mathrm{TF}$ magnets are not linked presents fewer engineering challenges and should lead to a more reliable design. Both the Type A and Type B curves have a minimum in major radius $R$ at a minimizing aspect ratio $A$ typically above 2.8 and at high values of magnetic field $B$ above $10 \mathrm{~T}$. The minimizing $A$ occurs at larger values for longer pulse and higher performance devices. The larger $A$ and higher $B$ design points also have the feature that the ratio of the discharge time to the current redistribution time is largest so that steady-state operation can be more realistically prototyped. A sensitivity study is presented for the baseline Type A configuration showing the dependence of the results on the parameters held fixed for the minimization study.
\end{abstract}




\section{Introduction:}

There is a growing consensus in the fusion community that it is time to proceed with the design, construction, and operation of a burning plasma experiment. This is reflected in the recent report from the Fusion Energy Sciences Advisory Committee entitled "Review of Burning Plasma Physics" [1]. The first of the recommendations from that report is that "Now is the time for the U.S. Fusion Energy Sciences Program to take the steps leading to the expeditious construction of a burning plasma experiment."

There are three general classes of magnet technologies that have been put forward for a next step burning plasma device. The most ambitious, and by all accounts the most costly, is that based on superconducting magnets. This necessarily leads to a large device, such as the ITER-FEAT design being developed by the European Union, Japan, and Russia [2], but one that also has the capability of very long pulse operation. It can be argued that a superconducting device will also serve to prototype many reactor-relevant technologies.

A second option is a water-cooled copper device [3]. This also leads to large size, and also could be operated for long pulses with the magnets in a thermal steady state.

The option we consider here is that of a compact high field tokamak utilizing copperalloy coils pre-cooled to liquid nitrogen temperatures. Several such burning plasma experiments have been proposed. [4-6]. Such a device can be significantly smaller and less expensive than a superconducting device or a water-cooled copper device, but has inherent limitations in pulse-length due to the fact that the magnets are subject to adiabatic heating during the pulse. Nevertheless, a design space exists for devices that can operate for many plasma energy confinement times and for several plasma current redistribution times, which should be adequate for studying the physics of a steady state burning plasma.

We use the term "compact" to indicate that the radial build of the device is minimized, and that the engineering parameters are up against their design limits for full field operation. We describe in this paper a systems-level code to assist in the design and optimization of such a device. We find that such a systems analysis provides insight as to the tradeoffs involved in choosing the engineering configuration, aspect ratio, and current and field strengths.

In the next section we describe the tokamak physics relations used in the systems analysis. Specifying a minimum set of performance parameters and equality and inequality constraints allows us to uniquely define the required plasma current and toroidal magnetic field for each value of the plasma major radius, $R$, and aspect ratio, $A$.

Two qualitatively different engineering configurations are introduced in Section III, which we call "tokamak-like" and "ST-like". Upon selection of one of these, and evaluation of the inductive requirements for producing and sustaining the required plasma current (in Section IV), we can calculate curves $R(A)$ that separate the accessible 
and inaccessible regions of the $(R, A)$ space. A machine design, with major radius and aspect ratio lying on this critical curve satisfies our definition of compact. These solutions are discussed in Section V, and we summarize in Section VI.

\section{Plasma optimization}

We consider a high-temperature tokamak plasma consisting primarily of Deuterium and Tritium but with some Helium ash and a small impurity content. For a fixed set of dimensionless tokamak physics parameters and inequality constraints, specifying the auxiliary input power, $P_{A U X}[\mathrm{MW}]$, and the toroidal magnetic field at the plasma center, $B$ [T], allows us to solve for the required plasma current, $I[\mathrm{MA}]$, and a minimum value of the plasma major radius for which energy balance is obtained, $R=R_{M I N}$. All of the other plasma parameters follow from the relations given in this section.

The dimensionless tokamak physics parameters we hold fixed are the energy multiplication ratio $Q \equiv P_{\text {fusion }} / P_{A U X}$, the aspect ratio $A$, some measure of the edge safety factor (either $q_{C Y L}$ or $q_{M H D}$ ) the energy confinement time multiplier $H(y, 2)$, the impurity fraction and charge, $f_{I M P}$ and $Z$, the temperature and density exponents $\alpha_{T}$ and $\alpha_{N}$, the plasma elongation and triangularity, $\kappa$ and $\delta$, and the ratio of particle to energy confinement time $\tau_{P} / \tau_{E}$. The inequality constraints are that the plasma density and beta be below a specified fraction of the Greenwald and Troyon limits as discussed below.

The plasma/vacuum boundary is taken to be a toroidal surface that is described by a major radius $R[\mathrm{~m}]$, a minor radius $a[\mathrm{~m}]$, an elongation $\kappa$ and a triangularity $\delta$. Thus, the aspect ratio is $A=R / a$, and the inverse aspect ratio is $\varepsilon=1 / A=a / R$. The plasma volume [in

$\left.\mathrm{m}^{3}\right]$ is $V_{P}=2 \pi^{2} a^{2} \kappa R$. The toroidal magnetic field at the plasma center (in the absence of plasma currents) is given as $B[\mathrm{~T}]$, and the total plasma toroidal current is $I$ [MA]. Two common approximations to the plasma safety factor are [7]:

$$
\begin{aligned}
& q_{C Y L}=\frac{5 a^{2} B}{I R}\left(\frac{1+\kappa^{2}}{2}\right), \\
& q_{M H D}=\frac{5 a^{2} B}{I R}\left(\frac{1+\kappa^{2}\left(1+2 \delta^{2}-1.2 \delta^{3}\right)}{2}\right)\left(\frac{1.17-0.65 \varepsilon}{\left(1-\varepsilon^{2}\right)^{2}}\right)
\end{aligned}
$$

We have the option of holding either of these fixed as we scan $A$. For the results presented in this paper, we hold $q_{C Y L}$ fixed, as this is more representative of the operational MHD stability limit at low values of $A$ than is holding $q_{M H D}$ fixed. Similarly, since the solutions normally optimize at the largest allowable values of plasma elongation $\kappa$, we have found it convenient to allow $\kappa$ to vary as a function of aspect ratio to approximate a constant margin to the axisymmetric stability limit for fixed wall separation [8]. Thus, in the aspect ratio scans presented here we set:

$$
\kappa(A)=1.73+1.47 \exp [-1.08(A-1)]
$$


[Note that this is a slightly stronger aspect ratio dependence than that found in [8] where the wall separation is held at a fixed fraction of the minor radius as $A$ varied rather than a fixed absolute distance]

The central values of the electron temperature and densities are given by $T_{e}[\mathrm{eV}]$ and $n_{e}$ $\left[\mathrm{m}^{-3}\right]$. We assume that the ion temperature is equal to the electron temperature, $T_{i}=T_{e}$, and that the plasma is charge neutral. If the hydrogen species are an equal mix of Deuterium and Tritium with central densities $n_{D}=n_{T}$, and there is also Helium and an impurity with charge $Z$ present with densities $n_{H e}$ and $n_{I}=f_{I M P} \times n_{e}$, then these are related to the electron density by

$$
n_{D}+n_{T}+2 n_{H e}=n_{e}\left(1-Z f_{I M P}\right)
$$

The quantity $Z_{E F F}$ that appears in the radiation calculation is given by

$$
Z_{E F F}=\left(n_{D}+n_{T}+4 n_{H e}+Z^{2} f_{I M P} n_{e}\right) / n_{e}
$$

Note that the central value of the total density of the electrons and the ions is given in terms of the other densities by:

$$
n_{\text {TOT }}=\frac{\left(n_{D}+n_{T}\right)\left[2-(Z-1) f_{\text {IMP }}\right]+n_{H e}\left[3-(Z-2) f_{I M P}\right]}{1-Z f_{I M P}}
$$

For the 0-D analysis used in the systems code, we assume that the temperatures and densities have a spatial distribution given by a simple dependence on the minor radius (in a toroidal coordinate system) of $\left[1-(r / a)^{2}\right]^{\alpha}$ where $\alpha=\alpha_{N}$ for the densities and $\alpha=\alpha_{T}$ for the temperatures. Thus, for example, the ratio of the peak to volume averaged electron temperature is given by: $T_{e} /\left\langle T_{e}\right\rangle=\alpha_{T}+1$.

With these conventions, we can define the thermal toroidal beta, $\beta_{T}$, the poloidal beta, $\beta_{P}$, and the Troyon normalized beta, $\beta_{N}$, as follows:

$$
\begin{aligned}
& \beta_{T}=C_{1} \frac{n_{T O T} T_{e}}{B^{2}\left(1+\alpha_{N}+\alpha_{T}\right)}, \\
& \beta_{P}=\beta_{T} q_{C Y L}^{2} \frac{2 A^{2}}{\left(1+\kappa^{2}\right)}, \\
& \beta_{N}=\beta_{T} \frac{a B}{I}
\end{aligned}
$$

Here $C_{1}=2.01 \times 10^{-22}\left[\mathrm{ev}^{-1} \mathrm{~m}^{3} \mathrm{~T}^{2}\right]$. Note that these quantities would in general have an additional non-thermal component due to the fast alpha particles. This is readily calculated, but is not required for the systems analysis presented in this paper. 
The inequality constraints are that the Troyon normalized thermal beta be below a preset limit [9], $C_{T}$, and that the line-averaged electron density be below a specified fraction, $f_{G W}$, of the Greenwald [10] density. Thus,

$$
\begin{aligned}
& \beta_{N} \leq C_{T}, \\
& \bar{n}_{e}\left[10^{20} \mathrm{~m}^{-3}\right] \leq f_{G W} \frac{I}{\pi a^{2}} .
\end{aligned}
$$

The line average and volume average values are related by $\bar{n}_{e}=\left(1+\frac{1}{2} \alpha_{N}\right)<n_{e}>$.

Let the total amount of externally supplied heating power to the plasma be $P_{A U X}[\mathrm{MW}$. If the total fusion power produced by the plasma is $Q \times P_{A U X}$, then the amount of alpha particle power produced is $P_{\alpha}=\frac{1}{5} Q \times P_{A U X}$. The total power lost by Bremsstrahlung radiation in these units is [11]

$$
P_{R A D}=C_{2} Z_{E F F} n_{e}^{2} T_{e} a^{2} R \kappa \frac{\left(1+\alpha_{N}\right)^{2}\left(1+\alpha_{T}\right)^{1 / 2}}{\left(1+2 \alpha_{N}+\frac{1}{2} \alpha_{T}\right)}(M W),
$$

where $C_{2}=4.8 \times 10^{-43}\left[\mathrm{MW} \mathrm{ev}^{-1} \mathrm{~m}^{3}\right] \quad=$ If the fraction of alpha power lost by radiation is $f_{R A D} \equiv P_{R A D} / P_{\alpha}$, then the total plasma heating power can be written as

$$
P_{T O T}=\left(1+\frac{5}{Q}-f_{R A D}\right) P_{\alpha} \text {. }
$$

It follows that the steady state volume averaged helium density can be written in terms of these quantities and the ratio of the particle to the energy confinement time:

$$
<n_{H E}>\left[10^{20} m^{-3}\right]=(0.0106) \frac{\beta_{N} I B}{a\left(1+\frac{5}{Q}-f_{R A D}\right)} \frac{\tau_{P}}{\tau_{E}} .
$$

The total alpha power is given by [12]:

$$
P_{\alpha}[M W]=C_{3} \int_{0}^{V_{P}}\left[n_{D}(V) n_{T}(V) e^{a_{0}+a_{*} T_{k e v}(V)^{-0.275}+a_{1} T_{k e v}(V)+a_{2} T_{k e v}(V)^{2}+a_{3} T_{k e v}(V)^{3}}\right] d V
$$

Here, the assumed minor radius dependence of the density and temperature [in kev] are included in the plasma volume integral, which is done numerically. The constants, in the units of this paper are: $C_{3}=5.6 \times 10^{-25}, a_{0}=-23.836, a_{*}=-22.712, a_{1}=-0.09393, a_{2}=$ 0.0007994 , and $a_{3}=-3.144 \times 10^{-6}$.

The plasma total stored energy and the ITER98[y,2] energy confinement time are given by[7]: 


$$
\begin{gathered}
W[M J]=(0.596) \beta_{N}(I B / a) V \\
\tau_{E}[s]=H(y, 2) c_{0} I^{c_{1}} R^{c_{2}} \varepsilon^{c_{3}} B^{c_{4}} \kappa^{c_{5}} \bar{n}_{e 19}{ }^{c_{6}} P_{T O T}{ }^{{ }^{c_{7}}} M^{c_{8}}
\end{gathered}
$$

with $c_{0}=0.028, c_{1}=0.93, c_{2}=1.97, c_{3}=0.58, c_{4}=0.15, c_{5}=0.78, c_{6}=0.41, c_{7}=0.69, c_{8}$ $=0.19$. $M$ is the average ion mass, taken to be 2.5 for an equal mix of DT, and $\bar{n}_{e 19}$ is the line averaged electron density in units of $10^{19}\left[\mathrm{~m}^{-3}\right]$.

The condition for energy balance is simply:

$$
\frac{W[M J]}{\tau_{E}[s]}=P_{T O T}[M W]
$$

In summary, if we prescribe $P_{A U X}, B$ and the plasma $q$ (either $q_{M H D}$ or $q_{C Y L}$ ), $Q, A, \kappa, f_{I M P}$, $Z, \alpha_{T}, \alpha_{N}, \tau_{P} / \tau_{E}, H(y, 2)$ and the inequality upper bounds $C_{T}$ and $f_{G W}$, then the relations given in this section are sufficient to determine the plasma current, $I$, and the values of the plasma density and temperature, $n_{e}$ and $T$, that satisfy energy balance at the minimizing value of $R$, i.e. $R=R_{M I N}\left(P_{A U X}, B, q, Q, A, \kappa(A), f_{I M P}, Z, \alpha_{T}, \alpha_{N}, \tau_{P} / \tau_{E}, H(y, 2)\right.$, $\left.C_{T}, f_{G W}\right)$.

Alternatively, for a given value of major radius $R$ and aspect ratio $A$, if we fix the parameters $P_{A U X}, q_{C Y L}, Q, \kappa(A), f_{I M P}, Z, \alpha_{T}, \alpha_{N}, \tau_{P} / \tau_{E}$, and $H(y, 2)$, and optimize the plasma density and temperature subject to the inequality constraints, $C_{T}$ and $f_{G W}$, the toroidal magnetic field $B$ [T] and plasma current $I$ [MA] required for energy balance are uniquely determined. These are illustrated in Figures 1 and 2 as contours in the parameter space $(R, A)$ for typical parameters as listed in columns 1 and 2 of Table 1.

The "Type A default" parameters listed in column 1 are typical of those proposed for a compact high field burning plasma experiment such as FIRE[6]. The power multiplication factor, $\mathrm{Q}=10$, makes it appropriate for studying strong self-heating, and we will see that the 20 s flattop time corresponds to many energy confinement times and a few current redistribution times over most of the parameter space. The energy confinement multiplier of $\mathrm{H}(\mathrm{y}, 2)=1.1$ is consistent with recent regression fits of experiments with these plasma shapes and densities [20].

The "Type B default" parameters listed in column 2 are much more modest. They aim at a power multiplication factor of only 2 assuming an agressive energy confinement multiplier of 1.4 , and with only a $5 \mathrm{~s}$ flattop time. These are more typical of what some are proposing for a next-step DTST experiment. [13]

In the following sections, we address which regions in each of these $(R, A)$ spaces are consistent with the engineering constrains and thus realizable. 


\begin{tabular}{|l|l|l|l|}
\hline symbol & description & Type A default & Type B default \\
\hline$P_{A U X}$ & Auxiliary power [MW] & 15 & 30 \\
\hline$q_{C Y L}$ & Cylindrical safety factor & 2.2 & 2.75 \\
\hline$Q$ & Power multiplication & 10 & 2.0 \\
\hline$\delta$ & Triangularity of 95\% surface & 0.4 & 0.3 \\
\hline$f_{I M P}$ & Species fraction of impurity & 0.03 & 0.03 \\
\hline$Z$ & Atomic charge of impurity & 4 & 4 \\
\hline$\alpha_{T}$ & Temperature exponent & 1.0 & 1.0 \\
\hline$\alpha_{N}$ & Density exponent & 0.2 & 0.2 \\
\hline$\tau_{P} / \tau_{E}$ & Ratio of particle to energy time & 5.0 & 5.0 \\
\hline$H(y, 2)$ & Multiplier of ITER98(y,2) & 1.1 & 1.4 \\
\hline$C_{T}$ & Maximum Troyon coefficient & .03 & .035 \\
\hline$f_{G W}$ & Maximum Greenwald fraction & 0.75 & 0.75 \\
\hline$h_{i}$ & Flux based internal inductance & 0.70 & 0.55 \\
\hline$C_{E}$ & Flux based Ejima coefficient & 0.20 & 0.15 \\
\hline$\Delta t_{F L A T}$ & Flattop time in seconds & 20 & 5.0 \\
\hline$g^{O H}$ & Gap associated with OH coil & $0.062 \mathrm{~m}$ & $0.062 \mathrm{~m}$ \\
\hline$g^{T F}$ & Gap associated with TF coil & $0.10 \mathrm{~m}$ & $0.017 \mathrm{~m}$ \\
\hline$g^{S O L}$ & Plasma Scrape-off layer & $0.08 \mathrm{~m}$ & $0.02 \mathrm{~m}$ \\
\hline
\end{tabular}

Table 1: Default parameters held fixed for the Type A and Type B configuration scans. 




Figure 1: Shown as contours are the values of plasma current (MA) and toroidal field (T) required at each value of major radius $\mathrm{R}[\mathrm{m}]$ and aspect ratio $\mathrm{A}$ in order that plasma energy balance be satisfied. Fixed parameters, listed in Column 1 of Table 1, are $P_{A U X}$, , $q_{C Y L} Q, \kappa(A), f_{I M P}, Z, \alpha_{T}, \alpha_{N}, \tau_{P} / \tau_{E}$, and $H(y, 2)$. The solid unnumbered curve is the minimizing $R(A)$ curve for Type A configurations, while the dotted unnumbered curve is $R(A)$ for Type B configurations with the same parameters. 


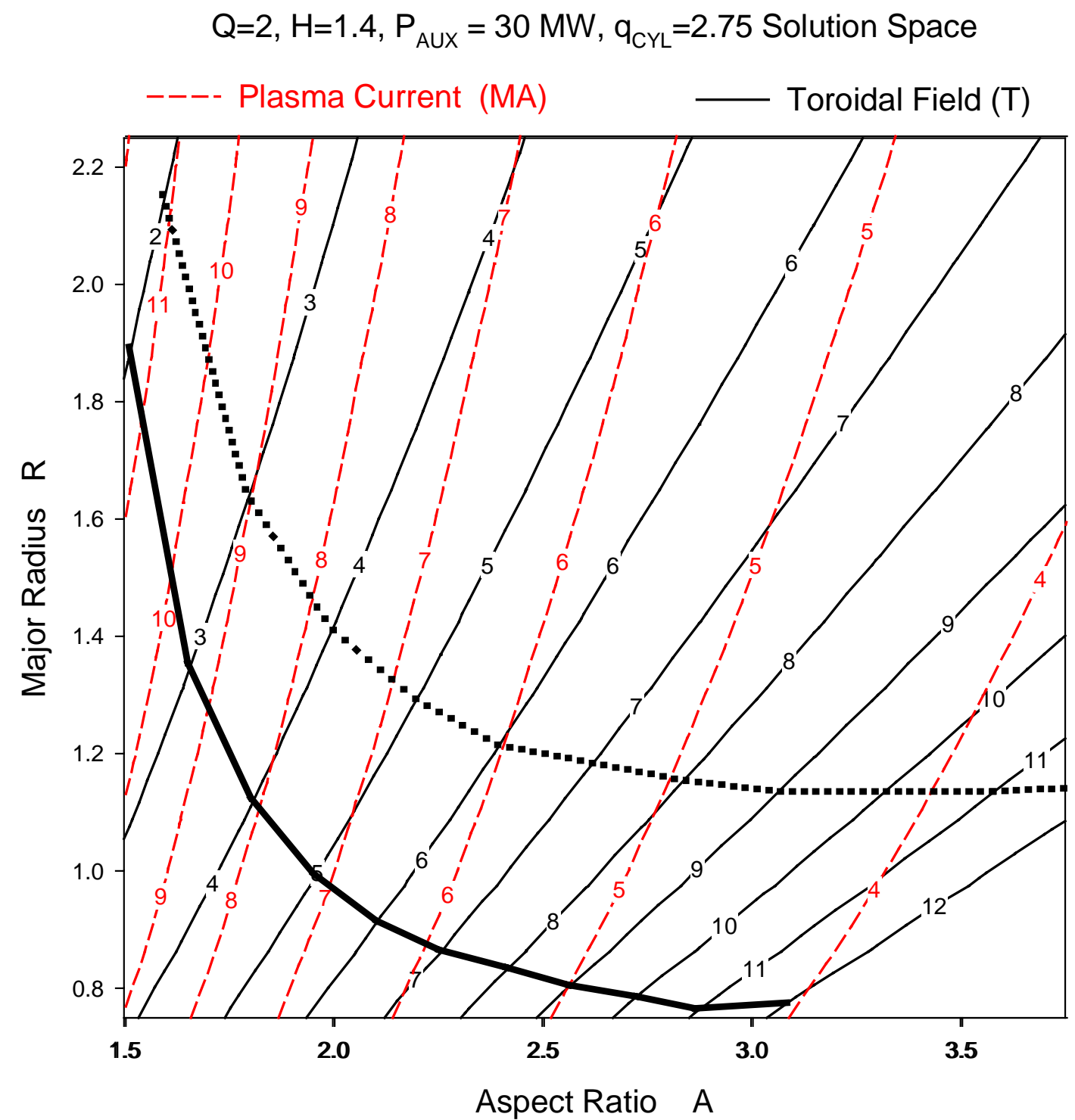

Figure 2: Shown as numbered contours are the values of plasma current (MA) and toroidal field $(\mathrm{T})$ required at each value of major radius $\mathrm{R}[\mathrm{m}]$ and aspect ratio $\mathrm{A}$ in order that plasma energy balance be satisfied. Fixed parameters, listed in Column 2 of Table 1, are $P_{A U X}, q_{C Y L}, Q, \kappa(A), f_{I M P}, Z, \alpha_{T}, \alpha_{N}, \tau_{P} / \tau_{E}$, and $H(y, 2)$. The solid unnumbered curve is the minimizing $R(A)$ curve for Type $\mathrm{B}$ configurations, while the dotted unnumbered curve is $R(A)$ for Type A configurations with the same parameters. 


\section{Radial Build and Engineering Constraints}

As discussed in Section I, the design of a "compact" burning plasma experiment necessarily concentrates on the radial build. We consider the two classes of configurations shown in Figure. 3. Type A is "Tokamak-like" with the Toroidal Field (TF) Coils and the Ohmic Heating $(\mathrm{OH})$ coils unlinked, and Type B is "ST-like" (Spherical Torus) with the TF and $\mathrm{OH}$ coils linked and the inner radius of the TF coil extending the whole way to the symmetry axis, $\mathrm{R}=0$. The Type $\mathrm{A}$ and $\mathrm{B}$ configurations are governed by the following radial build relations:

Type A: $R=R_{I}^{O H}+\Delta R^{O H}+g^{O H}+\Delta R^{T F}+g^{T F}+g^{S O L}+a$

Tyре $B: \quad R=\Delta R^{T F}+g^{T F}+\Delta R^{O H}+g^{O H}+g^{S O L}+a$

Here, as indicated in Figure 3, $R$ and $a$ are the plasma major and minor radii, $\Delta R^{O H} \equiv R_{O}^{O H}-R_{I}^{O H}$ is the radial thickness of the $\mathrm{OH}$ coil, $\Delta R^{T F} \equiv R_{O}^{T F}-R_{I}^{T F}$ is the radial thickness of the TF coil, and $g^{T F}, g^{O H}$ are the engineering gaps associated with TF and $\mathrm{OH}$ coils due to tolerances, electrical insulation, and thermal expansion, and $g^{S O L}$ is the plasma scrape-off layer, vacuum vessel, and first wall thickness. Thus, for the Type A configuration, $g^{T F}+g^{S O L}=R-a-R_{O}^{T F}, g^{O H}=R_{I}^{T F}-R_{O}^{O H}$, while for the Type B configuration, $g^{T F}=R_{I}^{O H}-R_{O}^{T F}, g^{O H}+g^{S O L}=R-a-R_{O}^{O H}$. We impose the additional requirement that the inside of the $\mathrm{OH}$ coil for the Type A configuration be at least $1 / 2$ the
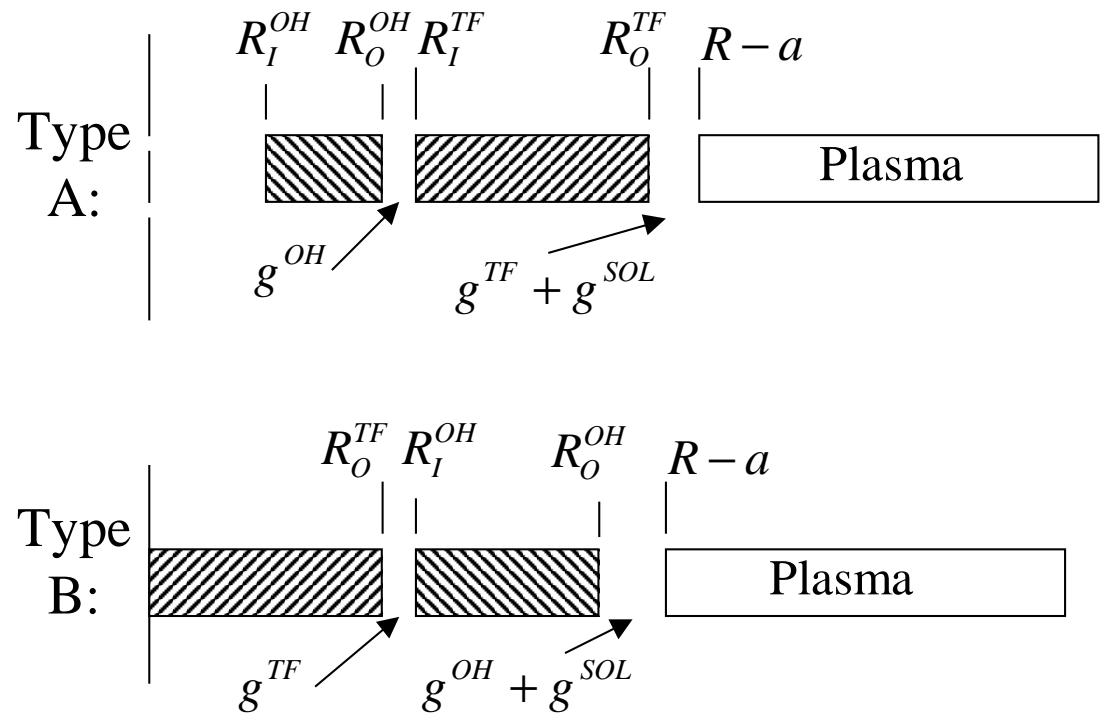

Figure 3: We consider two engineering configurations. Type $\mathrm{A}$ is the standard highfield tokamak configuration with the TF and $\mathrm{OH}$ coils unlinked. Type $\mathrm{B}$ is the ST-like configuration with the $\mathrm{TF}$ and $\mathrm{OH}$ linked, and the inner radius of the $\mathrm{TF}$ coil extending to the symmetry axis $\mathrm{R}=0$. 
outside radius, $R_{I}^{O H} \geq R_{O}^{O H}$ to keep the solution from becoming ill posed. (Note:

Recently it has been proposed to use this center void to add an auxiliary TF center post to the Type A configuration to increase the flexibility and compactness of this configuration [21]. This option will be explored in a future publication.)

\section{Inductive Requirements:}

A critical component of the inductive operation is estimating the poloidal flux swing required by the plasma current rampup, and flattop sustainment. We use the formulation provided by Hirshman and Neilson[14]. It should be noted that we are only interested in the flux-linkage that must be supplied by the $\mathrm{OH}$ coil, since it contributes to the radial build of the machine where the other poloidal field coils do not. The flux requirement for the $\mathrm{OH}$ coils is given by[in $\mathrm{W}$, or $\mathrm{V}$-sec]:

$$
\begin{aligned}
& \Delta \psi=\mu_{o} R I_{p}\left(l_{\text {ext }}+h_{i}+C_{E}+C_{\text {flat }} \Delta t_{\text {flat }}\right) \\
& C_{\text {flat }}=(.014)\left(T_{e} / 10 .\right)^{-1.5} Z_{\text {eff }} \\
& l_{\text {ext }}=l_{S}-\frac{m}{4}\left[\ln \left(\frac{8}{\varepsilon \sqrt{\kappa}}\right)+\beta_{p}+\frac{h_{i}}{2}-1.5\right] \\
& l_{S}=a_{1} \frac{(1-\varepsilon)}{\left(1-\varepsilon+a_{2} \kappa\right)} \\
& m=\frac{(1-\varepsilon)^{2}}{a_{3}(1-\varepsilon)^{2}+a_{4} \sqrt{\kappa}}
\end{aligned}
$$

Here, Ip is the plasma current in [A], $h_{i}$ is the flux-based internal inductance per unit length (defined as $\left.\Delta \Psi_{I N T} / \mu_{0} R I_{P}\right), C_{E}$ is the flux-based Ejima coefficient (defined as $\Delta \Psi_{A X I S} / \mu_{0} R I_{P}$ for the current rampup) $\Delta t_{\text {flat }}$ is the flattop time and the coefficients $a_{1}, a_{2}$, $a_{3}$, and $a_{4}$ can be found in [14]. The other symbols have their normal definitions as given in Section II.

\section{Results for Aspect Ratio Scans}

Using the techniques discussed in Section II, we are able to find the minimizing major radius, $R_{M I N}$, that gives energy balance for a given value of magnetic field $B$, aspect ratio $A$, and the other parameters being held fixed in the calculation: $P_{A U X}, q, Q, \kappa(A), \delta, f_{I M P}, Z$, $\alpha_{T}, \alpha_{N}, \tau_{P} / \tau_{E}, H(y, 2), C_{T}$, and $f_{G W}$. When we further specify the internal inductance $h_{i}$, the Ejima coefficient $C_{E}$, and the current flattop time $\Delta t_{F L A T}$, this implies an $\mathrm{OH}$ flux swing requirement $\Delta \psi$ as described in Section IV. After specifying the configuration type (I or II) and the gap sizes $g^{O H}, g^{T F}$, and $g^{S O L}$, we are able to evaluate whether the engineering constraints on the $\mathrm{OH}$ and TF coils are satisfied using the algorithms specified in Appendices A-D. 
If the engineering constraints are not satisfied, we do not have a self-consistent solution and the aspect ratio $A$ must be increased and the solution procedure repeated. If the engineering constraints are satisfied, we have found a solution but it is not necessarily the minimizing solution for the given physics and engineering constraints. We can then decrease the aspect ratio $A$, and look for another, more compact solution until $A$ takes on its critical value for that value of $B$. This can in turn be done for each value of the toroidal magnetic field $B$. In this way, we can define unique compact burning plasma minimizing curves $R(A)$ for both Type $\mathrm{A}$ and Type $\mathrm{B}$ configurations with the parameters $P_{A U X}, q_{C Y L}$ $Q, \kappa(A), \delta, f_{I M P}, Z, \alpha_{T}, \alpha_{N}, \tau_{P} / \tau_{E}, H(y, 2), C_{T}, f_{G W}, h_{i}, C_{E}, \Delta t_{F L A T}, g^{O H}, g^{T F}$, and $g^{S O L}$ held fixed. The toroidal magnetic field $B$ and plasma current $I$ will vary along these curves.

We have carried out this minimization for both the Type A and Type B configurations and present the results of typical parameter sets in Tables 2 and 3 and have superimposed these on Figures 1 and 2.

\begin{tabular}{|l|l|l|l|l|l|l|l|l|l|}
\hline $\mathrm{B}(\mathrm{T})$ & 12 & 11 & 10 & 9 & 8 & 7 & 6 & 5 & 4 \\
\hline $\mathrm{A}$ & 4.20 & 3.82 & 3.55 & 3.29 & 3.05 & 2.81 & 2.59 & 2.38 & 2.17 \\
\hline $\mathrm{R}(\mathrm{m})$ & 2.11 & 2.04 & 2.06 & 2.09 & 2.15 & 2.20 & 2.31 & 2.49 & 2.76 \\
\hline $\mathrm{I}(\mathrm{MA})$ & 6.76 & 7.42 & 8.05 & 8.77 & 9.59 & 10.57 & 11.71 & 13.12 & 14.96 \\
\hline$\kappa$ & 1.77 & 1.80 & 1.82 & 1.85 & 1.89 & 1.93 & 1.99 & 2.06 & 2.14 \\
\hline $\mathrm{q}_{\mathrm{MHD}}$ & 2.97 & 3.00 & 3.04 & 3.09 & 3.15 & 3.23 & 3.33 & 3.48 & 3.70 \\
\hline$\beta_{\mathrm{T}} \%$ & 1.80 & 2.02 & 2.22 & 2.48 & 2.77 & 3.15 & 3.64 & 4.23 & 5.06 \\
\hline$\beta_{\mathrm{N}} \%$ & 1.60 & 1.60 & 1.61 & 1.62 & 1.63 & 1.64 & 1.67 & 1.69 & 1.72 \\
\hline$\beta_{\mathrm{P}}$ & 0.74 & 0.67 & 0.63 & 0.59 & 0.55 & 0.51 & 0.47 & 0.44 & 0.41 \\
\hline $\mathrm{P}_{\mathrm{RAD}}(\mathrm{MW})$ & 12.5 & 12.1 & 12.3 & 12.5 & 12.4 & 12.2 & 12.5 & 12.2 & 12.3 \\
\hline $\mathrm{P}_{\mathrm{L}-\mathrm{H}}(\mathrm{MW})$ & 30.8 & 28.7 & 27.3 & 25.9 & 24.5 & 23.0 & 21.6 & 20.2 & 18.8 \\
\hline $\mathrm{P}_{\mathrm{LOSS}}(\mathrm{MW})$ & 32.4 & 32.8 & 32.7 & 32.4 & 32.6 & 32.7 & 32.6 & 32.8 & 32.7 \\
\hline$<\mathrm{n}_{\mathrm{e}}>10^{20} \mathrm{~m}^{-3}$ & 5.15 & 4.78 & 4.39 & 4.00 & 3.51 & 3.04 & 2.60 & 2.08 & 1.60 \\
\hline$<\mathrm{T}_{\mathrm{e}}>(\mathrm{keV})$ & 6.63 & 6.73 & 6.68 & 6.63 & 6.67 & 6.71 & 6.65 & 6.71 & 6.68 \\
\hline $\mathrm{f}_{\mathrm{GW}}$ & 0.65 & 0.637 & 0.637 & 0.637 & 0.625 & 0.612 & 0.612 & 0.60 & 0.60 \\
\hline $\mathrm{Z}_{\mathrm{EFF}}$ & 1.41 & 1.41 & 1.40 & 1.41 & 1.41 & 1.41 & 1.41 & 1.41 & 1.41 \\
\hline $\mathrm{f}_{\mathrm{RAD}}$ & 0.40 & 0.43 & 0.41 & 0.42 & 0.41 & 0.41 & 0.41 & 0.41 & 0.41 \\
\hline$\tau_{\mathrm{E}}(\mathrm{s})$ & 0.87 & 0.922 & 1.02 & 1.14 & 1.28 & 1.46 & 1.74 & 2.14 & 2.81 \\
\hline$\tau_{\mathrm{J}}(\mathrm{s})$ & 6.73 & 7.23 & 8.28 & 9.57 & 11.25 & 13.4 & 16.8 & 22.3 & 32.0 \\
\hline $\mathrm{f}_{\mathrm{BS}}$ & 0.22 & 0.22 & 0.21 & 0.20 & 0.20 & 0.19 & 0.18 & 0.18 & 0.17 \\
\hline $\mathrm{N}_{\mathrm{WALL}}\left(\mathrm{MW} / \mathrm{m}^{2}\right)$ & 2.43 & 2.34 & 2.13 & 1.91 & 1.67 & 1.45 & 1.20 & 0.94 & 0.68 \\
\hline $\mathrm{P}_{\mathrm{AUX}}(\mathrm{MW})$ & 15.0 & 15.0 & 15.0 & 15.0 & 15. & 15 & 15 & 15 & 15 \\
\hline
\end{tabular}

Table 2: Optimization results for a Type A "Tokamak-like" configuration using default parameters listed in column 1 of Table 1. 


\begin{tabular}{|l|l|l|l|l|l|l|l|l|l|l|l|}
\hline $\mathrm{B}(\mathrm{T})$ & 12 & 11 & 10 & 9 & 8 & 7 & 6 & 5 & 4 & 3 & 2 \\
\hline $\mathrm{A}$ & 3.09 & 2.87 & 2.73 & 2.57 & 2.42 & 2.26 & 2.11 & 1.96 & 1.81 & 1.66 & 1.52 \\
\hline $\mathrm{R}(\mathrm{m})$ & 0.77 & 0.76 & 0.78 & 0.80 & 0.83 & 0.86 & 0.91 & 0.99 & 1.12 & 1.35 & 1.89 \\
\hline $\mathrm{I}(\mathrm{MA})$ & 4.02 & 4.34 & 4.63 & 4.97 & 5.37 & 5.85 & 6.42 & 7.13 & 8.06 & 9.36 & 11.3 \\
\hline$\kappa$ & 1.88 & 1.93 & 1.96 & 2.00 & 2.05 & 2.10 & 2.17 & 2.25 & 2.34 & 2.45 & 2.57 \\
\hline $\mathrm{q}_{\mathrm{MHD}}$ & 3.67 & 3.75 & 3.82 & 3.92 & 4.03 & 4.20 & 4.42 & 4.73 & 5.20 & 5.94 & 7.16 \\
\hline$\beta_{\mathrm{T}} \%$ & 3.81 & 4.29 & 4.67 & 5.15 & 5.76 & 6.60 & 7.49 & 8.74 & 10.3 & 12.4 & 15.0 \\
\hline$\beta_{\mathrm{N}} \%$ & 2.85 & 2.88 & 2.90 & 2.91 & 2.96 & 3.01 & 3.03 & 3.10 & 3.17 & 3.23 & 3.30 \\
\hline$\beta_{\mathrm{P}}$ & 1.21 & 1.13 & 1.09 & 1.03 & 0.98 & 0.94 & 0.88 & 0.84 & 0.79 & 0.74 & 0.69 \\
\hline $\mathrm{P}_{\mathrm{RAD}}(\mathrm{MW})$ & 7.05 & 7.09 & 7.15 & 6.87 & 6.99 & 7.15 & 6.83 & 6.93 & 6.96 & 6.87 & 7.02 \\
\hline $\mathrm{P}_{\mathrm{L}-\mathrm{H}}(\mathrm{MW})$ & 10.7 & 10.0 & 9.65 & 9.18 & 8.73 & 8.22 & 7.75 & 7.29 & 6.85 & 6.47 & 6.28 \\
\hline $\mathrm{P}_{\mathrm{LOSS}}(\mathrm{MW})$ & 35.0 & 35.0 & 34.8 & 35.1 & 35.0 & 34.8 & 35.1 & 35.1 & 35.0 & 35.1 & 34.9 \\
\hline$<\mathrm{n}_{\mathrm{e}}>10^{20} \mathrm{~m}^{-3}$ & 13.2 & 12.6 & 11.3 & 9.94 & 8.85 & 7.83 & 6.41 & 5.22 & 3.97 & 2.66 & 1.44 \\
\hline$<\mathrm{T}_{\mathrm{e}}>(\mathrm{keV})$ & 5.42 & 5.41 & 5.39 & 5.48 & 5.44 & 5.39 & 5.50 & 5.47 & 5.45 & 5.49 & 5.43 \\
\hline $\mathrm{f}_{\mathrm{GW}}$ & 0.71 & 0.70 & 0.70 & 0.67 & 0.67 & 0.67 & 0.65 & 0.65 & 0.65 & 0.65 & 0.68 \\
\hline $\mathrm{Z}_{\mathrm{EFF}}$ & 1.37 & 1.37 & 1.37 & 1.37 & 1.37 & 1.37 & 1.37 & 1.37 & 1.37 & 1.37 & 1.37 \\
\hline $\mathrm{f}_{\text {RAD }}$ & 0.58 & 0.59 & 0.60 & 0.57 & 0.58 & 0.60 & 0.57 & 0.57 & 0.58 & 0.57 & 0.58 \\
\hline$\tau_{\mathrm{E}}(\mathrm{s})$ & 0.17 & 0.18 & 0.20 & 0.22 & 0.25 & 0.29 & 0.34 & 0.42 & 0.56 & 0.82 & 1.54 \\
\hline$\tau_{\mathrm{J}}(\mathrm{s})$ & 1.30 & 1.37 & 1.60 & 1.80 & 2.13 & 2.54 & 3.14 & 4.16 & 6.02 & 10.2 & 24.9 \\
\hline $\mathrm{f}_{\mathrm{BS}}$ & 0.43 & 0.42 & 0.41 & 0.40 & 0.39 & 0.39 & 0.38 & 0.37 & 0.37 & 0.36 & 0.35 \\
\hline $\mathrm{N}_{\mathrm{WALL}}\left(\mathrm{MW} / \mathrm{m}^{2}\right)$ & 5.22 & 5.00 & 4.43 & 3.95 & 3.43 & 2.96 & 2.43 & 1.89 & 1.36 & 0.84 & 0.38 \\
\hline $\mathrm{P}_{\mathrm{AUXX}}(\mathrm{MW})$ & 30.0 & 30.0 & 30.0 & 30.0 & 30.0 & 30.0 & 30.0 & 30.0 & 30.0 & 30.0 & 30.0 \\
\hline
\end{tabular}

Table 3: Optimization results for a Type B "ST-like" configuration using default parameters listed in column 2 of Table 1.

Note that in Tables 3 and 4 we have introduced several new parameters, the L-H transition threshold power $P_{L-H}[15]$, the total power crossing the separatrix $P_{L O S S}$, the current redistribution time $\tau_{J}[16]$, the bootstrap fraction $f_{B S}$, and the neutron wall loading $N_{\text {WALL }}$. These are defined as:

$$
\begin{aligned}
& P_{L-H}=1.14 B^{0.82} n_{e 19}^{0.58} R^{1.81} \varepsilon^{0.81} \\
& P_{L O S S}=P_{\alpha}+P_{A U X}-P_{R A D} \\
& \tau_{J}=\frac{\mu_{0}}{12\left\langle\eta_{N C}\right\rangle} a^{2} \kappa \\
& f_{B S}=\left(0.525+\frac{1}{2} \alpha_{N}\right) \sqrt{\varepsilon} \beta_{P} \\
& N_{\text {WALL }}=\frac{P_{\text {fusion }}}{\pi^{2} a R \sqrt{\frac{1+\kappa}{2}}}
\end{aligned}
$$

Here $\eta_{N C}$ is the plasma neoclassical resistivity as calculated in [17]. The design requirement that $P_{L O S S}>P_{L-H}$ is seen to be satisfied for all design points considered. We 
also see from both Tables 2 and 3 that the current redistribution time $\tau_{J}$ increases rapidly in these series as $A$ decreases. Thus for example, in Table 2, the desired goal of having the pulse length greater than two current redistribution times is only realized for the highaspect ratio, high field points with $A>3.3$ and $B>9 T$. In Table 3 , we see that this is satisfied for the points with $A>2.26$ and $B>7 T$.

We also note from the Tables 2 and 3 that none of the optimizing solutions are at the inequality limits for the normalized density or the normalized $\beta$. Thus, even though the inequality limits were imposed, they did not affect the optimized solution curves $R(A)$ for either configuration for the choice of the other parameters used.

\section{Equivalent Plasmas for $\mathrm{Q}=10, \mathrm{H}=1.1, \mathrm{~T}=20 \mathrm{~s}$, Type A default}

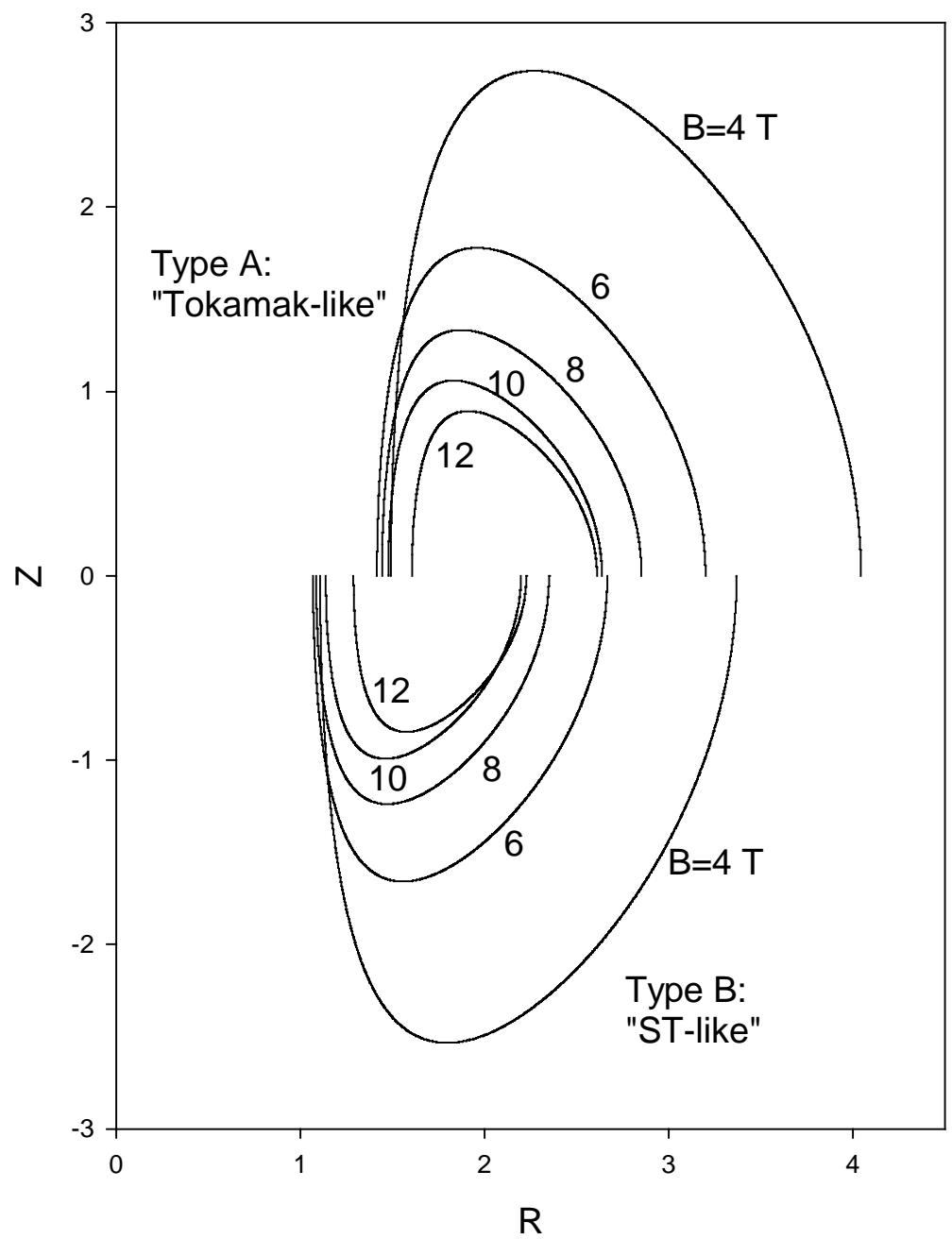

Figure 4: Plasma-vacuum boundaries corresponding to the two minimizing curves $R(A)$ on Figure 1. Other parameters used are those listed in column1 of Table 1. Each plasma, with the toroidal magnetic shown, satisfies physics and engineering constraints.

In each of Figures 2 and 3 we have drawn two (unnumbered) minimizing curves. The solid curve in Figure 1 corresponds to the Type A configuration with the parameters 
listed in Column 1 of Table 1. The dotted curve has all those same parameters the same (including coil gaps) but is for the Type B configuration. Similarly, the solid curve in Figure 2 corresponds to the Type B configuration with the parameters listed in Column 2 of Table 1. The dotted curve in that figure is for the Type A configuration with the same parameters. We see that all four curves have a minimum $R$ at some $A$, but the minimum is very shallow for the curves of Figure 2.

Equivalent Plasmas for $\mathrm{Q}=2, \mathrm{H}=1.4, \mathrm{~T}=5 \mathrm{~s}$, Type $\mathrm{B}$ default

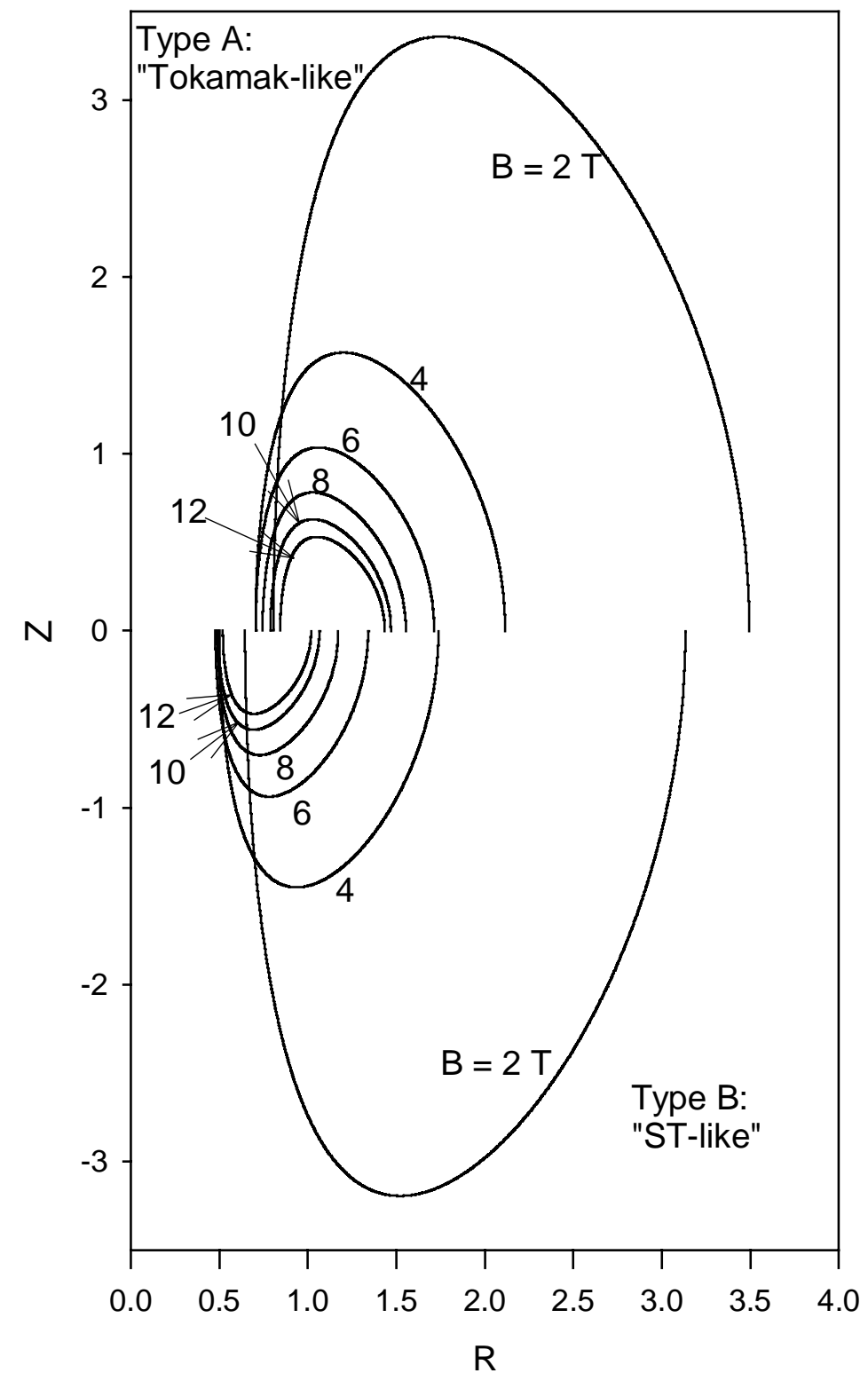


Figure 5: Plasma-vacuum boundaries corresponding to the two minimizing curves $R(A)$ on Figure 2. Other parameters used are those listed in column 2 of Table 1. Each plasma, with the toroidal magnetic shown, satisfies physics and engineering constraints.

In Figures 4 and 5 we have plotted the plasma-vacuum interfaces that correspond to the minimizing curves $R(A)$ in Figures 1 and 3. The figures are split, with the Type $\mathrm{A}$ "Tokamak-like" coil configurations being on the top, and the corresponding Type B "STlike" coil configurations on the bottom. The values of the toroidal magnetic field corresponding to each solution (in T) are shown on the figure.

There are several interesting trends that one can observe from Figures 4 and 5. The inner plasma boundary R-a for the Type A configuration always exceeds that for the equivalent Type B configuration. This is a result of the current carrying coils more effectively filling the interior volume. However, as previously discussed, this comes at the expense of having the $\mathrm{TF}$ and $\mathrm{OH}$ coils linked.

For the Type A configuration, as we go from the high aspect ratio, high field solutions to the lower aspect ratio lower field solutions, the R-a interface initially moves towards the axis, but eventually reaches a low-field limit where it starts to increase. This transition occurs near a toroidal field strength of 4-6 T for each of the configurations. It is due both to the fact that the plasma center is moving further from the coils as the aspect ratio increases, and the $\mathrm{OH}$ coils need to grow to provide more flux as the plasma current increases at low aspect ratio. For the Type B configuration, the R-a interface is almost independent of the aspect ratio for the intermediate field cases. As the aspect ratio and the toroidal field are increased, the increase in the build of the TF coil is almost exactly compensated by the decrease in the build of the $\mathrm{OH}$ coil.

Similarly, for both the Type A and Type B configurations, as we go to the higher aspect ratio, higher field solutions, the $\mathrm{R}+\mathrm{a}$ interface location initially decreases rapidly, but at $\mathrm{B}$ $>10 \mathrm{~T}$, the rate of decrease slows, and the interface $\mathrm{R}+\mathrm{a}$ actually starts to increase at the highest fields for the Type B curves in Figure 4. Thus, it would appear that there is no advantage to these highest fields where both the magnet volume inside $\mathrm{R}-\mathrm{a}$ and the outer plasma radius $\mathrm{R}+\mathrm{a}$ increase with field strength.

\section{Sensitivity to Parameters}

We have systematically varied each of the nominal parameters around the Type A baseline values listed in column 1 of Table 1 . The results are listed in Table 4 for coil configuration Type A, "Tokamak-like". In generating this table, we have fixed all the parameters at their baseline values. For this study, we have also kept the baseline $q_{M H D}$ at 3.04 , and the baseline elongation $\kappa$ at 1.82 , even as the aspect ratio $A$ changes. The magnetic field at the plasma center was held fixed at $10 \mathrm{~T}$, and for each set of parameters, the aspect ratio was varied to find the critical value of plasma major radius $R$ for which a solution exists. We see that modest changes in parameters can be accommodated by very modest changes in major radius $R$. 


\begin{tabular}{|l|l|l|l|l|l|l|l|}
\hline parameter & name & value & baseline & $\begin{array}{l}\% \\
\text { change }\end{array}$ & $\mathrm{A}$ & $\mathrm{R}$ & $\begin{array}{l}\% \\
\text { change }\end{array}$ \\
\hline baseline & & & & & 3.54 & 2.06 & \\
\hline Multiplier of ITER98 $\tau_{\mathrm{E}}$ & $\mathrm{H}(\mathrm{y}, 2)$ & 1.2 & 1.1 & $+9.1 \%$ & 3.68 & 1.96 & $-4.8 \%$ \\
\hline Multiplier of ITER98 $\tau_{\mathrm{E}}$ & $\mathrm{H}(\mathrm{y}, 2)$ & 1.0 & 1.1 & $-9.1 \%$ & 3.40 & 2.19 & $+6.3 \%$ \\
\hline Plasma elongation & $\kappa$ & 1.72 & 1.82 & $-5.5 \%$ & 3.38 & 2.15 & $+4.4 \%$ \\
\hline Plasma elongation & $\kappa$ & 1.92 & 1.82 & $+5.5 \%$ & 3.70 & 1.98 & $-3.9 \%$ \\
\hline Pulse length $(\mathrm{s})$ & $\tau$ & 10 & 20 & $-50 \%$ & 3.34 & 1.89 & $-8.3 \%$ \\
\hline Pulse length $(\mathrm{s})$ & $\tau$ & 40 & 20 & $+100 \%$ & 3.87 & 2.35 & $+14 \%$ \\
\hline Edge safety factor & $\mathrm{q}_{\mathrm{MHD}}$ & 3.25 & 3.04 & $+6.9 \%$ & 3.42 & 2.12 & $+2.9 \%$ \\
\hline Edge safety factor & $\mathrm{q}_{\mathrm{MHD}}$ & 2.85 & 3.04 & $-6.2 \%$ & 3.66 & 2.01 & $-2.4 \%$ \\
\hline Energy multiplication & $\mathrm{Q}$ & 5 & 10 & $-50 \%$ & 3.75 & 1.92 & $-6.8 \%$ \\
\hline Energy multiplication & $\mathrm{Q}$ & 20 & 10 & $+100 \%$ & 3.40 & 2.16 & $+4.8 \%$ \\
\hline $\begin{array}{l}\text { Ratio of particle to energy } \\
\text { confinement time }\end{array}$ & $\tau_{\mathrm{P}} / \tau_{\mathrm{E}}$ & 2 & 5 & $-60 \%$ & 3.58 & 2.04 & $-1.0 \%$ \\
\hline $\begin{array}{l}\text { Ratio of particle to energy } \\
\text { confinement time }\end{array}$ & $\tau_{\mathrm{P}} / \tau_{\mathrm{E}}$ & 10 & 5 & $+100 \%$ & 3.46 & 2.12 & $+2.9 \%$ \\
\hline Impurity fraction & & & & & & & \\
\hline Impurity fraction & $\mathrm{f}_{\mathrm{IMP}}$ & .05 & .03 & $+66 \%$ & 3.42 & 2.18 & $+5.8 \%$ \\
\hline Density exponent & $\mathrm{f}_{\mathrm{IMP}}$ & .01 & .03 & $-66 \%$ & 3.64 & 1.98 & $-3.9 \%$ \\
\hline Density exponent & $\alpha_{\mathrm{N}}$ & 0.1 & 0.2 & $-50 \%$ & 3.51 & 2.10 & $+1.9 \%$ \\
\hline Temperature exponent & $\alpha_{\mathrm{N}}$ & 0.3 & 0.2 & $+50 \%$ & 3.57 & 2.03 & $-1.4 \%$ \\
\hline Temperature exponent & $\alpha_{\mathrm{T}}$ & 1.2 & 1.0 & $+20 \%$ & 3.59 & 2.01 & $-2.4 \%$ \\
\hline & $\alpha_{\mathrm{T}}$ & 0.8 & 1.0 & $-20 \%$ & 3.49 & 2.12 & $+2.9 \%$ \\
\hline
\end{tabular}

Table 4: Results of a sensitivity study around the baseline Type A configuration listed in Column 1 of Table 1.

\section{Discussion and Summary}

We have described a new systems code that is useful for the preliminary design and optimization next step compact burning plasma fusion experiments. We demonstrated how the physics rules will define a unique plasma current and toroidal magnetic field strength for each point in a $(R, A)$ design space, and how the engineering constraints will then define a critical curve in that same space separating the points that are realizable from those that are not.

We considered two classes of magnet design: Type A, which were "Tokamak-like" and had the feature that the $\mathrm{OH}$ and TF coils were not linked, and Type B, which were "STlike" and do have linked $\mathrm{OH}$ and TF magnets. In all cases examined, the Type B curves lay below the Type A curves for the same physics parameters, indicating that they led to 
a more compact design. However, the fact that the Type A OH and TF magnets are not linked should lead to simplified engineering and a more reliable design.

We also found that both the Type A and Type B curves have a minimum in major radius $R$ at an aspect ratio $A$ above 2.8 and at a high magnetic field $B$ above $10 \mathrm{~T}$. The minimizing $A$ occurs at larger values for longer pulse and higher performance devices. The larger $A$, higher $B$, design points also have the feature that the ratio of the discharge time to the current redistribution time is larger, so they can more realistically prototype steady state operation.

The analysis presented here should provide some insight regarding the choice of parameters for the next step burning plasma experiments. This analysis could readily be extended to provide information regarding power supply requirements and device costs, and well as capability for long pulse operation at reduced parameters. The actual decisions regarding which design point to choose will take all these considerations into account, as well as how this next machine will complement the world's fusion development program. 


\section{Appendix A: Type A “Tokamak-like" OH calculation}

If the $\mathrm{OH}$ coil stack has height $h=a \times \kappa$, inner and outer radii $R_{I}$ and $R_{O}$, and is required to produce a flux swing $\Delta \psi[\mathrm{W}]$, then the required current swing [A] is

$$
\Delta I_{O H}=\Delta \psi \frac{\left(h^{2}+R_{M}^{2}\right)^{1 / 2}}{\mu_{0} h} \frac{3\left(R_{O}-R_{I}\right)}{\pi\left(R_{O}^{3}-R_{I}^{3}\right)}
$$

This is evaluated as a conventional double-swing $\mathrm{OH}$ coil. The time dependence of the current in the ohmic heating $(\mathrm{OH})$ coil is such that the plasma current has a ramp-up time of $1 \mathrm{MA} / \mathrm{s}$, and the pre-charge is the same rate in MA/s as the current ramp-up phase. The coil is initially at a temperature of $T_{0}=80^{\circ} \mathrm{K}$ and the fraction of the coil not occupied by conductor is $f=0.17$. The conductor has a mass density $\rho=8.89 \times 10^{3}$. We model the temperature dependence of the coil resistivity and thermal capacity as:

$$
\begin{aligned}
& \eta(T)=\eta_{0}\left[1+a_{1}(T-80)\right] \\
& \log _{10} C_{P}(T)=C_{0}+C_{1} \log _{10} T+C_{2} \log _{10}^{2} T+C_{3} \log _{10}^{3} T+C_{4} \log _{10}^{4} T
\end{aligned}
$$

where $\eta_{0}=0.25 \times 10^{-8}, a_{1}=0.0295, C_{0}=1.131, C_{1}=-9.454, C_{2}=12.99, C_{3}=-5.501, C_{4}=$ 0.7637 . The temperature is then integrated in time as:

$$
T(t)=T_{0}+\int_{0}^{t_{f}} \frac{\eta(T) J^{O H}(t)^{2}}{\rho C_{P}(T)} d t
$$

and the requirement is that the temperature not rise above $373^{\circ} \mathrm{K}$ at the end of the current rampdown, $t=t_{\mathrm{f}}$.

The requirement on the $\mathrm{OH}$ stress is calculated as

$$
\begin{aligned}
& \sigma_{O H}^{1}=1.85\left(\sigma_{\theta}-\sigma_{R}+\sigma_{V}\right) \leq 350 \\
& \sigma_{O H}^{2}=1.40\left(f_{I}\left[\sigma_{\theta}-\sigma_{R}\right]+\sigma_{V}\right) \leq 350-0.47\left(T_{E O B}-80\right)
\end{aligned}
$$

where $\sigma_{O H}[\mathrm{Mpa}]$ are average stress values for the plate coils, $\sigma_{\theta}, \sigma_{V}, \sigma_{R}$ are averaged values of the hoop stress, radial stress, and vertical stress as defined in Appendix B of [18] with a filling factor of $1 /(1-0.15)$, and $f_{I}$ is a reduction factor defined in that same reference to take into account the field introduced by the plasma current at End of Burn. 


\section{Appendix B: Type A “Tokamak-like” TF Calculation}

The current in the toroidal field (TF) coil is assumed to have a $20 \mathrm{sec}$ rise time and a 10 sec rampdown time. The coil is initially at a temperature of $T_{0}=80^{\circ} \mathrm{K}$. If $R_{I}^{T F}$ and $R_{O}^{T F}$ are the inner and outer radii of the TF coil, then the coil current density is:

$$
J^{T F}(t)=\frac{2 R B(t)}{\mu_{0}(1-f)\left(R_{O}^{T F^{2}}-R_{I}^{T F^{2}}\right)}
$$

where $f=0.175$ is the fraction of the coil not occupied by conductor. The conductor has a mass density $\rho=8.89 \times 10^{3}$. We model the temperature dependence of the coil resistivity and thermal capacity as:

$$
\begin{aligned}
& \eta(T)=\eta_{0}\left[1+a_{1}(T-80)\right] \\
& C_{P}(T)=C_{0}+C_{1} T+C_{2} T^{2}
\end{aligned}
$$

where $\eta_{0}=1.0 \times 10^{-8}$ [Ohm-m], $a_{1}=0.0091, C_{0}=104.5, C_{1}=1.883, C_{2}=-0.002987$. The temperature is then integrated in time as:

$$
T(t)=T_{0}+\int_{0}^{t_{f}} \frac{\eta(T) J^{T F}(t)^{2}}{\rho C_{P}(T)} d t
$$

and the requirement is that the temperature not rise above $373^{\circ} \mathrm{K}$ at the end of the current rampdown, $t=t_{\mathrm{f}}$.

The requirement on the TF stress is calculated as

$$
\sigma_{T F}=1.45\left(\sigma_{T R}+2 \times \sigma_{S H}\right) \leq 800-\left(T-80^{\circ}\right)
$$

where the Tresca stress $\sigma_{T R}$ (in Mpa) is defined as the maximum of $\left|\sigma_{\theta}-\sigma_{V}\right|,\left|\sigma_{\theta}-\sigma_{R}\right|,\left|\sigma_{R}+\sigma_{V}\right|$, and the shear stress $\sigma_{S H}$ is taken to be $30 \mathrm{MPa}$ for these calculations. The calculation of the average radial stress $\sigma_{R}$, the average hoop stress $\sigma_{\theta}$, and the average vertical stress $\sigma_{V}$ are taken from the wedged coil equations in Appendix $\mathrm{B}$ of [18], with a filling factor of $1 /(1-0.15)$. 


\section{Appendix C: Type B "ST-like" OH Calculation}

The $\mathrm{OH}$ conductor materials will be cooled to liquid nitrogen $\left(\mathrm{LN}_{2}\right)$ temperature $(80 \mathrm{~K})$ prior to the pulse and allowed to heat to $373 \mathrm{~K}(100 \mathrm{C})$ at the end of the pulse. Optimum performance is realized when materials are operated at their low temperature stress limit at SOP and their high temperature stress limit at EOFT, and at their thermal limit at EOP. Toward this end an asymmetry in the $\mathrm{OH}$ current waveform can be chosen to optimized performance. Assuming that the EM stress is due to Ioh only, then

$$
\frac{I_{1}}{I_{2}}=\sqrt{\frac{\sigma_{\text {cold }}}{\sigma_{\text {hot }}}} \equiv K_{\text {asym }}
$$

To maximize the flux swing available from the $\mathrm{OH}$ we use a two part $\mathrm{OH}$ coil. Studies have shown that such a coil can increase the flux by $50 \%$ compared to a constant current density all-copper coil. The outer coil is wound with copper $(\mathrm{Cu})$ conductor and is operated at a current density such that the material is at both thermal and mechanical limits. The minimum inner radius of the outer coil is determined by the allowable hoop stress. Then the inner coil is wound with a beryllium copper $(\mathrm{BeCu})$ alloy material (C17510) and is operated at a current density such that the material is at either its thermal or mechanical allowable, which ever is limiting.

The total $\mathrm{I}^{2} \mathrm{~T}$ of the $\mathrm{OH}$ pulse is

$$
\begin{aligned}
\sum I^{2} T & =I_{1}^{2}\left(\frac{t_{1}}{3}+\frac{t_{2}}{3}\right)+I_{2}^{2}\left(\frac{t_{3}}{3}+t_{4}+\frac{t_{5}}{3}\right) \\
& =I_{1}^{2}\left(\frac{t_{1}}{3}+\frac{t_{2}}{3}\right)+\frac{I_{1}^{2}}{K_{\text {assm }}^{2}}\left(\frac{t_{3}}{3}+t_{4}+\frac{t_{5}}{3}\right)
\end{aligned}
$$

With equivalent square wave $(\mathrm{ESW})$ current $\mathrm{I}_{\mathrm{ESW}}=\mathrm{I}_{1} \ldots$

$$
T_{E S W}=\left(\frac{t_{1}}{3}+\frac{t_{2}}{3}\right)+\frac{\left(\frac{t_{3}}{3}+t_{4}+\frac{t_{5}}{3}\right)}{K_{a s y m}^{2}}
$$

Curve fits are used to develop $\mathrm{G}\left(=\mathrm{J}^{2} \mathrm{~T}_{\text {esw }}\right)$ functions for $\mathrm{Cu}$ and $\mathrm{BeCu}$ over the temperature range of interest.

$$
\begin{gathered}
G_{C u}(T)=-6.45 E 16+1.02 E 15 T-2.61 E 12 T^{2}+2.74 E 9 T^{3} \\
G_{B e C u}(T)=-1.54 E 16+1.93 E 14 T-3.02 E 10 T^{2}+1.41 E 8 T^{3}
\end{gathered}
$$

The current density $\mathbf{J}$ which is allowable given a temperature limit $\mathrm{T}_{\text {allow }}$ can be determined as

$$
J=\sqrt{\frac{G\left(T_{\text {allow }}\right)-G\left(T_{0}\right)}{T_{E S W}}}
$$


Given a packing fraction $\mathrm{K}_{\mathrm{pf}}$, then, the allowable current density has an average value of

$$
J_{a v g}=J K_{p f}
$$

The following formulae are used to estimate the conductor stress in the $\mathrm{OH}$ solenoid. Axial stress (relatively small) is ignored, and only the hoop stress is considered. For a two part $\mathrm{OH}$ solenoid, on the outer coil, the maximum hoop stress occurs at the inner bore of the coil [19] and can be estimated as follows.

$$
\sigma=J * B\left\{\begin{array}{l}
\frac{\left[(7+5 v) \mathrm{R}_{\mathrm{o}}{ }^{4}-8(2+v) \mathrm{R}_{\mathrm{o}} \mathrm{R}_{\mathrm{i}}{ }^{3}+3(3+v) \mathrm{R}_{\mathrm{i}}{ }^{4}\right]}{24\left(\mathrm{R}_{\mathrm{o}}-\mathrm{R}_{\mathrm{i}}\right)\left(\mathrm{R}_{\mathrm{o}}{ }^{2}-\mathrm{R}_{\mathrm{i}}{ }^{2}\right)} \\
-\frac{(1+2 v) \mathrm{R}_{\mathrm{o}} \mathrm{R}_{\mathrm{i}}}{3\left(\mathrm{R}_{\mathrm{o}}-\mathrm{R}_{\mathrm{i}}\right)}+\frac{(1+3 v) \mathrm{R}_{\mathrm{i}}{ }^{2}}{8\left(\mathrm{R}_{\mathrm{o}}-\mathrm{R}_{\mathrm{i}}\right)} \\
+\frac{\mathrm{R}_{\mathrm{o}}{ }^{2}}{24}\left[\frac{\left.(7+5 v) \mathrm{R}_{\mathrm{o}}{ }^{2}-8(2+v) \mathrm{R}_{\mathrm{o}} \mathrm{R}_{\mathrm{i}}+3(3+v) \mathrm{R}_{\mathrm{i}}{ }^{2}\right)}{\left(\mathrm{R}_{\mathrm{o}}-\mathrm{R}_{\mathrm{i}}\right)\left(\mathrm{R}_{\mathrm{o}}{ }^{2}-\mathrm{R}_{\mathrm{i}}{ }^{2}\right)}\right.
\end{array}\right\}
$$

Here $R_{o}$ is the outer radius of the conductor pack, $R_{i}$ is the inner radius of the conductor pack, $v$ is Poisson's Ratio, and B is the field within the bore of the outer coil due to its own current

$$
B=\mu_{0} J_{\text {avg }}\left(R_{o}-R_{i}\right) * f f
$$

Where ff is the form factor which accounts for the finite length of the coil

$$
f f=\frac{\Delta Z}{\sqrt{\Delta Z^{2}+\left[\frac{\left(R_{o}+R_{i}\right)}{2}\right]^{2}}}
$$

and $\Delta \mathrm{Z}$ is the height of the coil. The height of the $\mathrm{OH}$ coil needs to exceed that of the plasma to reduce leakage flux and minimize stray vertical field. Based on NSTX, a ratio between $\mathrm{OH}$ coil height and plasma height in the range 1.2 to 1.4 is assumed.

On the inner coil, the maximum hoop stress occurs at the inner bore of the coil, due to its own current plus the $\mathrm{J} \times \mathrm{B}$ force with the background field of the outer coil

$$
\sigma=\mathrm{J} * \mathrm{~B}\left\{\frac{(2+v)\left\lfloor 2 \mathrm{R}_{\mathrm{o}}{ }^{2}+\mathrm{R}_{\mathrm{o}} \mathrm{R}_{\mathrm{i}}+\mathrm{R}_{\mathrm{i}}{ }^{2}-\frac{\left(\mathrm{R}_{\mathrm{o}}+\mathrm{R}_{\mathrm{i}}\right)(1+2 v) \mathrm{R}_{\mathrm{i}}}{2+v}\right]}{3\left(\mathrm{R}_{\mathrm{o}}+\mathrm{R}_{\mathrm{i}}\right)}\right\}
$$

Here $R_{o}$ and $R_{i}$ are the outer and inner radii of the inner coil, $J$ is the current density of the inner coil, and B is field due to the outer coil. Finally, the double swing flux produced by each part of the $\mathrm{OH}$ coil is equal to 


$$
\Phi_{d s}=f f * \frac{\mu_{0} \pi J_{a v g}}{3}\left(R_{o}^{3}-R_{i}^{3}\right)\left(1+1 / K_{a s y m}\right)
$$

\section{Appendix D: Type B “ST-like” TF Algorithm}

Thermal performance of the coil is assessed by performing a simple simulation of the TF current waveform. The required current from $\mathrm{N}$ turns is

$$
N I=2 \pi \frac{R_{o} B}{\mu_{0}}
$$

The inductance is obtained by integrating the flux enclosed as follows...

$$
\Phi=\int_{0}^{r o u t e r} \frac{\mu_{0} I}{2 \pi r} H(r) d r
$$

where I is the current enclosed, which linearly increases from zero at $r=0$ to the full current I at the outer radius of the inner legs, and H(r) is the height of the bore of the coil, assumed equal to "height" out through the horizontal limbs, and then linearly decreasing to zero thereafter over the distance " $\Delta r_{\text {pouter }}$. Then the inductance is...

$$
L_{t f}=\frac{\Phi N^{2}}{I}
$$

The total resistance of $\mathrm{N}$ series inner legs of the coil is...

$$
R_{\text {inner }}=\rho \frac{L N}{A_{\text {conductor }}}
$$

where L is assumed equal to "height" and $\rho$ is the resistivity which varies with temperature. Curve fits were used to develop a function for the specific heat of copper as follows.

$$
Q_{C u}(T)=-82.35+4.95 T-0.19 T^{2}+2.5 E-5 T^{3}
$$

For small increments, temperature rise is approximated as...

$$
\Delta T \approx \frac{I^{2} R}{Q(T)}
$$

Outer leg resistance is assumed constant and equal to a particular of the inner leg resistance at maximum temperature.

A dump resistor, normally shorted out, can be introduced into the TF circuit in case the power supply trips at full load current, thereby reducing the L/R decay time constant and the additional dissipation which must be anticipated in the design of the coil. Circuit behavior is simulated using simple Euler integration 


$$
\Delta I=\frac{\left[V_{p s o c}-I\left(R_{p s}+R_{\text {inner }}+R_{\text {outer }}\right)\right] \Delta t}{L}
$$

Flat top must end when the prospective temperature rise due to an L/R decay of the current, including the dump resistor, would bring the final temperature to the limit. This is estimated by taking the total stored magnetic energy, apportioning it between the inner and outer legs and dump resistor in proportion to their resistances, and dividing by the heat capacity

$$
\Delta T_{L R}=\frac{\left[1 / 2 L I^{2}\right] \frac{R_{\text {inner }}}{\left(R_{\text {inner }}+R_{\text {outer }}+R_{\text {dump }}\right)}}{Q}
$$

\section{Acknowledgements}

The authors gratefully acknowledge many useful discussions with their colleagues at PPPL and with the members of the FIRE engineering team, in particular J. Schultz, P.Heitzenroeder, and P. Titus, on the development and the application of the BPSC. This research was sponsored by the U.S. Department of Energy Office of Fusion Energy Sciences under contract DE-AC02-76CH03073, with Princeton University. 


\section{References}

[1] Fusion Energy Sciences Advisory Committee Report "Review of Burning Plasma Physics", DOE/SC-0041 September, 2001, U.S. Department of Energy, Office of Science.

[2] R. Aymar, V. A. Chuyanov, T.Huguet, Y. Shimomura, "Overview of ITER-FEATThe future international burning plasma experiment”, Nucl Fusion 41 p 1301-1310 (2001)

[3] J.L. Duchateau, F.Albajar, J.M. Ane, et al., "Optimization of the Magnetic System of a 200 MW Steady State Tokamak", IEEE Transactions on Applied Superconductivity, 10 p 624-627 (2000)

[4] B. Coppi, A. Airoldi, F. Bombarda et al, "Optimal regimes for ignition and the Ignitor experiment”, Nucl Fusion 41 p 1253-1257 (2001)

[5] R. Goldston, "Burning Plasma-Experiment Physics Design Description”, Fusion Technology, 21 p 1050-1055 (1992)

[6] D. Meade, "Fusion Ignition Research Experiment (FIRE)", Fusion Technology 39, p 336-342 (2001)

[7] F.W. Perkins, et al., "ITER Physics Basis”, Nuclear Fusion, 39, p 2137 (1999)

[8] R. Stambaugh, L. Lao, and E. Lazarus, "Relation of Vertical Stability and Aspect Ratio in Tokamaks", Nuclear Fusion, 32, p1642 (1992)

[9] F. Troyon, et al., MHD-Limits to Plasma Confinement,", Proc. $11^{\text {th }}$ European Conf. Controlled Fusion and Plasma Physics, Aachen, FRG, Sept 5-9, 1983, P. 209, A. Gobson, Ed., Pergamon Press (1984)

[10] M. Greenwald J.L. Terry, S.M. Wolfe, et al., "A new look at density limits in Tokamaks", Nuclear Fusion 28 p 2199-2207 (1988)

[11] S. Glasstone and R.H. Loveberg, Controlled Thermonuclear Reactions (Van Nostrand, New York, 1960), Chapt. 2.

[12] L.M. Hively, "Convenient Computational Forms for Maxwellian Reactivities", Nuclear Fusion, 17, p 873-876 (1977)

[13] C. Neumeyer, "Spherical Torus Center Stack Design”, Proceedings of $19^{\text {th }}$ SOFE conference. 
[14] S.P. Hirshman and G. H. Neilson, "External Inductance of an Axisymmetric Plasma", Phys. Fluids, 29, p 790 (1986)

[15] F.W. Perkins, et al, ., "ITER Physics Basis”, Nuclear Fusion, 39, p 2192 (1999)

[16] D. Mikkelsen, "Current Relaxation-Time Scales in Toroidal Plasmas", Phys Fluids B 1 p 333 (1989)

[17] S. Hirshman, R. Hawryluk, B.Birge, "Neoclassical Conductivity of a Tokamak Plasma”, Nucl. Fusion 17 p 611 (1977)

[18] J.D. Galambos, D. T. Blackfield, Y-K. Martin Peng, et al, "Systems Studies of Compact Ignition Tokamaks", Fusion Technology, 13, p 93 (1988)

[19] R. Roark \& W. Young, Formulas for Stress \& Strain, McGraw-Hill, p. 50

[20] G. Cordey,, "Energy Confinement Scaling in Steady-State ELMy H-Modes in JET" in " $28^{\text {th }}$ EPS Conference on Contr. Fusion and Plasma Physics, 2001, P3.11

[21] S.C. Jardin, U.S. DOE Patent Disclosure (2001) 


\section{External Distribution}

Plasma Research Laboratory, Australian National University, Australia

Professor I.R. J ones, Flinders University, Australia

Professor J oão Canalle, Instituto de Fisica DEQ/IF - UERJ , Brazil

Mr. Gerson O. Ludwig, Instituto Nacional de Pesquisas, Brazil

Dr. P.H. Sakanaka, Instituto Fisica, Brazil

The Librarian, Culham Laboratory, England

Library, R61, Rutherford Appleton Laboratory, England

Mrs. S.A. Hutchinson, JET Library, England

Professor M.N. Bussac, Ecole Polytechnique, France

Librarian, Max-Planck-Institut für Plasmaphysik, Germany

J olan Moldvai, Reports Library, MTA KFKI-ATKI, Hungary

Dr. P. Kaw, Institute for Plasma Research, India

Ms. P.J . Pathak, Librarian, Insitute for Plasma Research, India

Ms. Clelia De Palo, Associazione EURATOM-ENEA, I taly

Dr. G. Grosso, Instituto di Fisica del Plasma, Italy

Librarian, Naka Fusion Research Establishment, J AERI, J apan

Library, Plasma Physics Laboratory, Kyoto University, J apan

Research Information Center, National Institute for Fusion Science, J apan

Dr. O. Mitarai, Kyushu Tokai University, J apan

Library, Academia Sinica, Institute of Plasma Physics, People's Republic of China

Shih-Tung Tsai, Institute of Physics, Chinese Academy of Sciences, People's Republic of China

Dr. S. Mirnov, TRINITI, Troitsk, Russian Federation, Russia

Dr. V.S. Strelkov, Kurchatov Institute, Russian Federation, Russia

Professor Peter Lukac, Katedra Fyziky Plazmy MFF UK, Mlynska dolina F-2, Komenskeho Univerzita, SK-842 15 Bratislava, Slovakia

Dr. G.S. Lee, Korea Basic Science Institute, South Korea

Mr. Dennis Bruggink, Fusion Library, University of Wisconsin, USA

Institute for Plasma Research, University of Maryland, USA

Librarian, Fusion Energy Division, Oak Ridge National Laboratory, USA

Librarian, Institute of Fusion Studies, University of Texas, USA

Librarian, Magnetic Fusion Program, Lawrence Livermore National Laboratory, USA

Library, General Atomics, USA

Plasma Physics Group, Fusion Energy Research Program, University of California at San Diego, USA

Plasma Physics Library, Columbia University, USA

Alkesh Punjabi, Center for Fusion Research and Training, Hampton University, USA

Dr. W.M. Stacey, Fusion Research Center, Georgia Institute of Technology, USA

Dr. J ohn Willis, U.S. Department of Energy, Office of Fusion Energy Sciences, USA

Mr. Paul H. Wright, Indianapolis, Indiana, USA 
The Princeton Plasma Physics Laboratory is operated by Princeton University under contract with the U.S. Department of Energy.

\author{
Information Services \\ Princeton Plasma Physics Laboratory \\ P.O. Box 451 \\ Princeton, NJ 08543
}

Phone: 609-243-2750

Fax: 609-243-2751

e-mail: pppl_info@pppl.gov

Internet Address: http://www.pppl.gov 